\title{
Esoteric and occult Sweden
}

DOI: https://doi.org/10.30664/ar.102464

(c)( Attribution 4.0 International (CC BY 4.0)

Per Faxneld, Det ockulta sekelskiftet.

Esoteriska strömningar i Hilma af Klints tid (Stockholm: Volante, 2020), 237 pp.

While esoteric movements such as Theosophy and Anthroposophy are thoroughly international phenomena, they also have local and national dimensions with particular emphases and representatives. Per Faxneld's work on the 'occult turn of the century' describes the international settings and currents of esotericism, but focuses on their embodiments in Sweden. As the subtitle - esoteric currents in the age of Hilma af Klint - suggests, the focus is on the, at the moment highly popular, Swedish spiritual artist Hilma af Klint (1862-1944) and her coeval colleagues, Lucie Lagerbielke (1865-1931) and Tyra Kleen (1874-1951).

The objective of Per Faxneld's book is to give an easy-to-read introduction to the fuzzy concepts of esotericism and occultism, as well as their research, for readers not familiar with them beforehand. This means that the first part of the book does not provide much new for readers already versed in the subject, while the rest of the book which focuses on the esoteric and occult history in Sweden and its influences on Swedish art, offers much inspiring reading and new insights.

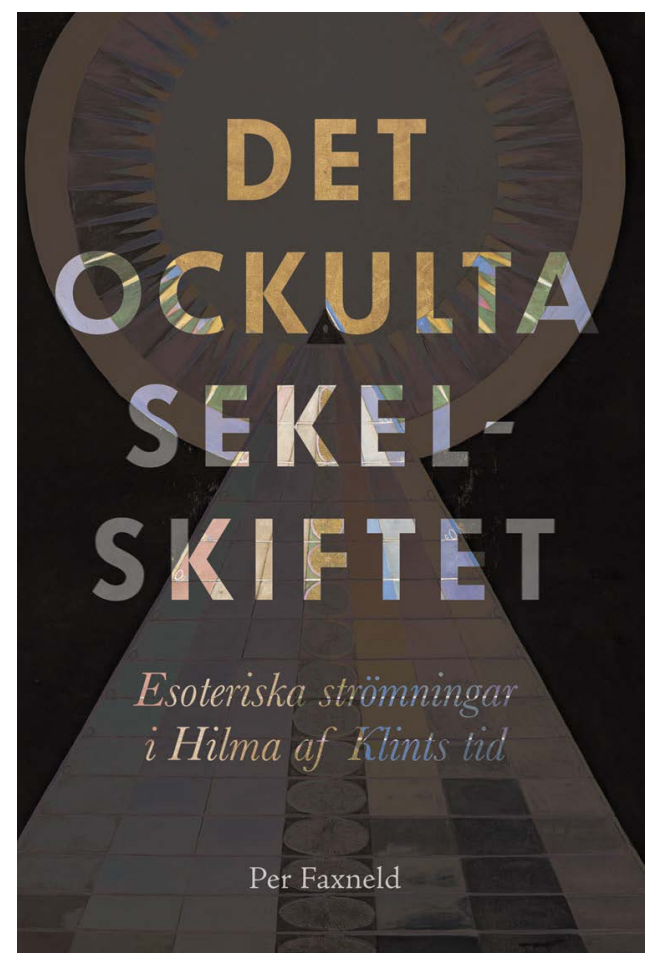

The focus of the book is on the turn of the twentieth century, but it also looks back in time as well as forward. In addition to Faxneld's text the book also contains a short afterword, written by a relative of Hilma af Klint which, however, mainly repeats what has already been said. The appended afterword is explained by the affiliation of the book to art exhibitions held in Stockholm at the time of its publication. Det ockulta 
sekelskiftet is a book which is nice to hold and read; it is extremely well written, has a beautiful layout, and is extensively illustrated.

\section{The esoteric and occult history of Sweden}

As the focus of the work is on Hilma af Klint and her art, it follows that it emphasises the movements, persons, and ideas that were important to her - but also people and characters which more broadly speaking belong to the Swedish esoteric and occult scene receive short introductions, and readers in need of more information may easily turn to works mentioned in the references. Because Finns and Swedes share a common history till the early nineteenth century, a Finnish reader finds many familiar names and events. Some interesting details may be gathered, for instance, in the connection of esotericism and occultism with the Swedish nobility and royal dynasty. As heads and patrons of Freemasonry, kings employed both magicians and alchemists - to which belonged, among others, the two prominent Finns Gustaf Björnram (1746-1804) and August Nordenskiöld (1754-92).

In exploring the early stages of these esoteric currents, Faxneld describes especially the traditions of alchemy and Rosicrucianism, as well as the history of Freemasonry. Due to the Swedish context it is reasonable that Emanuel Swedenborg (1688-1772) receives a chapter of his own. Faxneld does not go into more detail, for example, as regards August Nordenskiöld and his brother Carl Fredrik's role in the publishing and translating of Swedenborg's literary oeuvre. Having access to the legacy of Swedenborg, August Nordenskiöld presented at the first Swedenborgian Conference, which took place in London in 1789, views of Swedenborg concerning sex, love and gender, from hitherto unknown and unpublished manuscripts, such as
Swedenborg's dream diary. Amongst those who attended were none other than William Blake with his wife Catherine, the former being one of the most celebrated artists to have been influenced and inspired by the ideas of Swedenborg. Of Swedish authors, Faxneld mentions for instance P. D. A. Atterbom (1790-1855), C. J. L. Almqvist, Ivan Aguéli (1869-1917), and of course, August Strindberg (1849-1912).

In addition to artists Swedenborg also inspired movements such as Spiritualism, which started in the early nineteenth century, both in the US in the form of medium séances, and in Europe, interpreted especially by Allan Kardec (1804-69). In Sweden Kardec's doctrine of spirits, spiritism, became the most widespread form, whereas in Finland the Anglo-American concept of spiritualism gained prevalence. In Sweden, thus, the term spiritism became a designation of all kinds of communications with spirits.

At the turn of the nineteenth century trance mediumism was a popular activity both in private homes as well as in public séances. These included both questions to spirits posed by participants, table turning and even the appearance of ectoplasm - materialisations of spirits - produced by mediums. Faxneld proposes an interesting description of the development of Swedish spirtualism through its central actors, to which belonged Hilma af Klint and her group De Fem. Spiritualist communities at the time in general rarely offered women opportunities for experiencing agency and leadership. The Spiritualist movement in Sweden was thus intimately connected to the first-wave feminist movement. The early years of the Theosophical movement in Sweden were more broadly also connected to new ideologies of the late nineteenth century: liberalism, freedom of religion, women's affairs, and new trends in 
art. Famous artists interested in Theosophy were, for instance, Viktor Rydberg, Selma Lagerlöf, and Carl and Karin Larsson.

It is interesting to notice similarities and differences in the history of esoteric movements in Finland and in Sweden. While Theosophy in Finland became affiliated with the working class, in Sweden it attracted suffragettes and the nobility. The reception in Sweden was mainly in the form of the Theosophical branch of Katherine Tingley (1847-1929), who also visited Sweden and received an audience from King Oscar II, who had a personal interest in Theosophy. Anthroposophical meetings were organised in Sweden as early as in 1913 by army officials, and members came from both upper and middle classes, as well as from representatives of the nobility.

Artists also encountered the Anthroposophical movement. Hilma af Klint visited the headquarters of the movement in Switzerland, Goetheanum, several times in the 1920s, nourishing hopes that her temple paintings would be deposited there. Faxneld also highlights the Finnish poet Edith Södergran (1892-1923), who in her last years came to be influenced by Rudolf Steiner's thinking.

Faxneld does not mention the Finnish Anthroposophist Uno Donner and his influence on the Swedish Anthroposophical movement. Donner supported the society financially and also participated in its activities during World War One, when he was living in Stockholm with his wife Olly Donner, nowadays a largely forgotten author of Anthroposophical novels.

\section{Gender and esotericism: female artists}

The history of esotericism and occultism is more or less a history of male practitioners, writers, and artists, researched and written by male researchers. For this reason it is significant that Faxneld dedicates the main part of his work to presenting three female artists in Sweden: besides Hilma af Klint who today is known by almost everyone, it is instructive to learn about the more unknown artists Lucie Lagerbielke and Tyra Kleen.

While Lagerbielke, according to Faxneld, does not rank with more proficient artists, she was an important figure due to her ideas about the spiritual meaning of art. Lagerbielke's paintings were channelled by the spiritual visions which led her paintings, as were also fictional texts from contemporary authors. Presenting the connections of esotericism and art to the reading audience of Sweden, Lagerbielke was a celebrity in her own time, being a familiar figure in the press, as well as her writings being widely read.

Like Hilma af Klint, Tyra Kleen was an educated and skilful artist. A cosmopolite, Kleen studied and painted in different parts of Europe. In a slightly speculative manner Faxneld tries to map the possible connections between Kleen and other well-known artists, such as Edvard Munch, in tracing the sources of her inspirations. In Kleen's art a typical and characteristic topic is a feminist and Theosophical interpretation of the serpent of Eden - a familiar topic in Faxneld's earlier researches as well.

The most well-known and valued of the three artists is, of course, Hilma af Klint, whose exhibition at the Guggenheim Museum in New York has attracted huge audiences. Concerning the main themes of af Klint's known life and art works, Faxneld also proves that some of them are false. Hilma af Klint, for instance, did not demand her works to be kept secret and unavailable for decades. Af Klint didn't work alone, but was a member of the groups De Fem and De Tretton, whose working methods are extremely interesting but not yet properly researched. Both were Spiritualist groups 
exclusively for women, in which they were able to converge in studies and strive for spiritual development. At the same time they broke radically with much of what was conventionally possible and permitted at the time. The women shared, for instance, holy communion amongst themselves alone, although of course in secret.

Of these early artists Hilma af Klint remains the only one to be recognised in contemporary art history. Engaged in Spiritualism, Theosophy, and Anthroposophy, she presented her work to Rudolf Steiner, joined the Anthroposophical Society and visited Goetheanum where she studied Goethe's colour palette, which in many ways influenced her future art works.

The large legacy of Hilma af Klint consists of approximately 1,300 artworks and 124 notebooks with 26,000 pages, all more or less unexplored, so there is plenty of research in the pipeline - I'm looking forward to Hedvig Ahlén-Martin's forthcoming dissertation on the topic.

Esotericism has not gone away since its peak during the fin de siècle; it has continued and developed through the development of various movements and organisations and has from time to time become more visible in the mainstream media and cultural productions. Subsequent to the finde-siècle era it took the form of surrealism within visual and literal art, and became, to a certain extent, connected to nationalism and national socialism in the 1930s. Spiritualism became especially important during and after World War Two for people in mourning and seeking contact with their lost relatives. After the war esotericism emerged in new forms; for instance in humanistic psychology, parapsychological experiments and UFO phenomena - as part of the counterculture of the post-war generation, and from the 1980 os onwards within New Age and other new and alternative spiritualities. Today esoteric and occult interests are mainstream and popular. We can find it in the ideas of artists, authors, cartoon makers, musicians, and in movies, tv series and video games. Because of this, researchers of contemporary art, literature and popular culture should be aware of the long and intricate history of esotericism and occultism.

\section{Tiina Mahlamäki}

Tiina Mahlamäki is University Lecturer in the Study of Religion, University of Turku. 